\title{
Gabapentin as an adjuvant therapy to splinting in carpal tunnel syndrome (CTS): a systematic review and meta-analysis of randomized controlled trials
}

\author{
Ahmed M. Ahmed ${ }^{1}$ (D) Osama G. Hassan ${ }^{2}$ (D) and Ahmed A. Khalifa ${ }^{1 *}$ (D)
}

\begin{abstract}
Background: Carpal tunnel syndrome (CTS) is a common upper limb entrapment neuropathy; severe cases are treated surgically and mild to moderate can be managed conservatively. The purpose of this systematic review and meta-analysis was to define the efficacy of gabapentin as an adjuvant to splinting in the treatment of mild to moderate CTS.

Methods: A systematic search through 13 databases, randomized clinical trials (RCTs) reporting the use of gabapentin with splinting in CTS were included and analyzed.

Results: Three RCTs including 170 patients were eligible. There was no significant difference between gabapentin plus splinting and splinting alone in 5 measured parameters: (1) Symptom Severity Scale (SSS) $[M D(95 \%$ CI) = $0.76(-2.46-0.93), p=0.378]$, (2) Functional Status Scale (FSS) [MD (95\% Cl) $=-0.23(-1.40-0.94), p=0.701]$, (3) visual analogue scale (VAS) to assess pain [MD $(95 \% \mathrm{Cl})=-0.6(-1.47-0.27), p=0.174]$, (4) Grip strength [MD (95\% $\mathrm{Cl})=-0.11(-0.70-0.48), p=0.718]$, and (5) pinch strength [MD $(95 \% \mathrm{Cl})=0.72(-0.10-1.54), p=0.083]$.

Conclusion: This review provides low-quality evidence that gabapentin plus nocturnal splinting is not superior to splinting alone. More high-quality trials are needed to determine the role of this drug as an adjuvant in the management of CTS.
\end{abstract}

Keywords: Gabapentin, Splinting, Carpal tunnel syndrome, Systematic review, Meta-analysis

\section{Introduction}

Carpal tunnel syndrome (CTS) is a chronic compressive neuropathy resulting from compression of the median nerve at the wrist and considered to be the most common type of upper limb entrapment neuropathy seen in adults in outpatient clinics [1]. It affects $5.3 \%$ of women and $2.1 \%$ men [2]. It has a prevalence rate of $7.8 \%$ and an annual incidence rate of $5.7 \%$ in the working population [3].

\footnotetext{
* Correspondence: ahmed_adel0391@med.svu.edu.eg 1 Orthopedic and Traumatolgy Department, Qena Faculty of Medicine and University Hospital, South Valley University, Qena, Egypt Full list of author information is available at the end of the article
}

Although surgical treatment ensures relief of symptoms, it should be only indicated in severe cases with persistent symptoms because of the high cost and possible complications such as infection, nerve injury, tendon injury, and complex regional pain syndrome [4].

Conservative measures are considered as the first-line treatment in mild or moderate cases such as splints, non-steroidal anti-inflammatory drugs, physical therapy, and local steroid injections [5].

Wrist splinting and immobilization in a neutral position is the most popular conservative modality. Oral treatments such as Gabapentin, an antiepileptic drug structurally related to gama-amino butyric acid (GABA), is proposed to be effective for the treatment of 
neuropathic pain as diabetic neuropathy and postherpetic neuralgia [6,7]. According to Hui et al. [8], its benefit as a monotherapy in the management of CTS is limited. Its benefit, however, as an adjuvant to splinting is still controversial [9-11].

Therefore, the purpose of this systematic review and meta-analysis was to determine the effectiveness of gabapentin as an adjuvant to splinting versus splinting alone as a conservative line of CTS management.

\section{Methods}

\section{Search strategy and selection criteria}

Two reviewers independently performed an electronic search on 13 databases to retrieve all potentially relevant articles to the research subject. These databases included PubMed, Scopus, Embase, Google Scholar, Cochrane Central Register of Controlled Trials (CENTRAL), International Scientific Indexing (ISI), POPLINE, Global Health Library (GHL), Virtual Health Library (VHL), The New York Academy of Medicine (NYAM), WHO International Clinical Trials Registry Platform (ICTRP), ClinicalTrials.gov, and System for Information on Grey Literature in Europe (SIGLE). The following search terms were used together searching for all related articles: [gabapentin OR Neurontin OR pregabalin OR Lyrica OR Gaba OR anticonvulsant OR anticonvulsants] AND [(carpal tunnel) OR (entrapment neuropathy) OR (median neuropathy) OR (compression neuropathy) OR CTS]. There was no search filtering applied regarding language, year, and design. Results from scanned databases were grouped into one Endnote library to remove duplications. Two reviewers independently screened titles and abstracts of articles imported into Endnote for eligibility concerning inclusion and exclusion criteria. We included RCTs reporting the use of gabapentin as an adjuvant to splinting as a conservative line of CTS management. Exclusion criteria were (I) study designs other than RCTs, (II) severe cases of CTS required surgical intervention, (III) data cannot be extracted, (IV) overlapped data set, (V) only abstract is available, and (VI) duplication and irrelevant data. A manual search was carried out using references of the included studies, looking for similar articles in PubMed and Google Scholar. Decisions after reviewers' discussion were further upheld by consulting the senior author. The study selection procedure is summarized in the PRISMA flow diagram (Fig. 1).

\section{Data extraction}

Similar to the screening method, two reviewers were responsible for data extraction. A template in Microsoft Excel was used to report baseline characters and inspected outcomes. Further amendments were applied after reviewers' discussion. All data has been checked by the senior author.

\section{Statistical analysis}

All data were analyzed using $\mathrm{R}$ statistical software version 3.4.3 [12]. First, mean difference (MD), standardized mean difference (SMD), and associated standard errors (Se) were calculated for the intervention (gabapentin plus splinting) versus control (splinting alone) groups. All data were pooled with the help of "meta" package $[13,14]$. A fixed-effect model with the method of Mantel-Haenszel [15] was used when there is no evidence of heterogeneity between studies. Otherwise, a random-effects model with the method of DerSiomonian and Laird was chosen [16]. Heterogeneity between studies was evaluated using the Q statistic and $I^{2}$ test which describes the percentage of variability in the effect estimates $[16,17]$.

\section{Results \\ Literature search and patient characteristics}

The electronic search yielded 566 references from the 13 databases. After excluding duplicates and title/abstract screening, we had 24 relevant articles for full-text screening. Only three studies [9-11] fulfilled the inclusion criteria, and the manual search of references did not import any additional articles. The eligible three articles included 170 participants (100 intervention and 70 control) collectively, the mean age for intervention and control was 43.8 (SD; 8.1) and 47.18 (SD; 10.7) years, respectively. Patients' characteristics of each study are summarized in (Table 1). All three studies included only patients with mild to moderate idiopathic CTS. Degree of severity was defined based on clinical findings such as thenar atrophy and EMG findings. The following criteria describe the EMG findings that may be encountered in mild, moderate, and severe cases:

Mild: median distal sensory peak latency prolongation, either absolute or relative (using sensitive comparative methods) and no evidence of axon loss.

Moderate: abnormal median sensory latency, as noted in the mild type, and absolute or relative prolongation of median motor distal latency (using sensitive comparative methods), and lack of evidence of axon loss.

Severe: any disturbances in nerve conduction studies mentioned above, along with evidence of axon loss, defined as (a) lack or decreased amplitude of sensory nerve action potential or mixed nerve action potential of median nerve, (b) lack of or decreased amplitude of thenar compound muscle action potential, or (c) the presence of fibrillation potentials or changes in motor unit potentials such as increasing amplitude, duration, or phases in needle EMG [18]. 


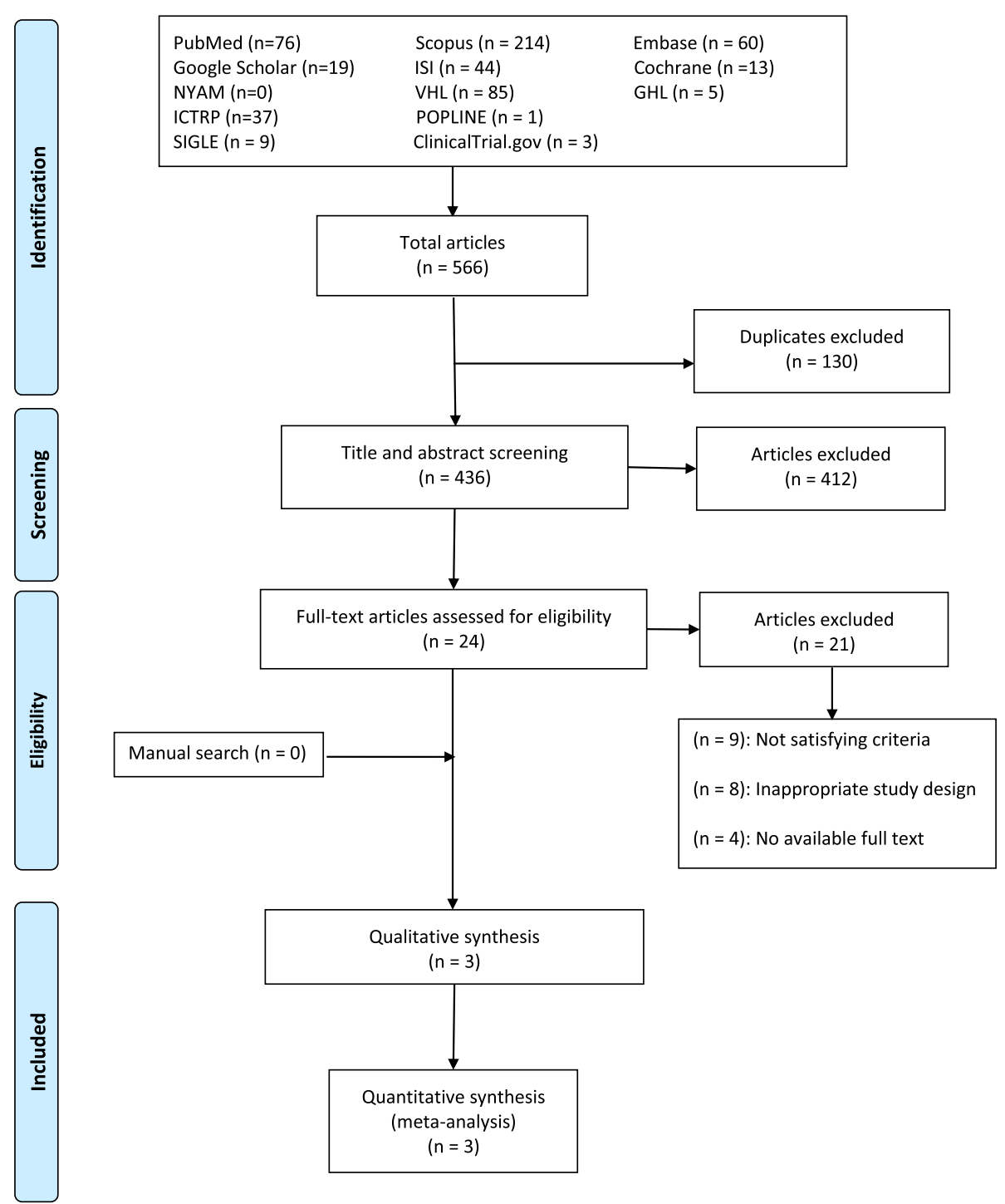

Fig. 1 PRISMA flow diagram of studies' screening and selection

\section{Quality assessment of included studies}

In order to assess the risk of bias among included RCTs, we used the Cochrane Collaboration's quality assessment tool [19]. Two reviewers independently carried out the assessment, and dissimilarities were settled by discussing with the senior author. The three included RCTs had a low risk of bias regarding selective reporting and attrition bias. Random sequence generation and allocation concealment were unclear in studies by Eftekharsadat et al. [9] and Mehmetoglu et al. [11] (Fig. 2)

The included studies evaluated the use of gabapentin plus splinting by observing changes in the following five parameters (clinical and electrophysiological).

Symptom Severity Scale (SSS): pooling of changes in SSS reported by the three studies showed no significant difference between intervention and control groups before and after treatment [MD $(95 \% \mathrm{CI})=-0.76(-$ 2.46-0.93), $p=0.378$ ] (Fig. 3a). A significant heterogeneity was found between studies $\left[I^{2}=96 \%, p<0.000\right]$.

Functional Severity Scale (FSS): regarding FSS fluctuations (pre- and post-treatment), results showed no significant difference between intervention and control groups $[\mathrm{MD}(95 \% \mathrm{CI})=-0.23(-1.40-0.94), p=0.701]$ (Fig. 3b) with significant heterogeneity $\left[I^{2}=93 \%, p<0.000\right]$.

Visual Analogue Score (VAS): monitoring effects of gabapentin using changes in pain assessed by VAS (preand post-treatment), there was no significant difference between intervention and control groups [MD (95\% CI) $=-0.6(-1.47-0.27), p=0.174]$ (Fig. 3c) with evidence of heterogeneity $\left[I^{2}=87.3 \%, p<0.000\right]$.

Grip strength: as for the changes in grip strength, no significant difference between intervention and control 


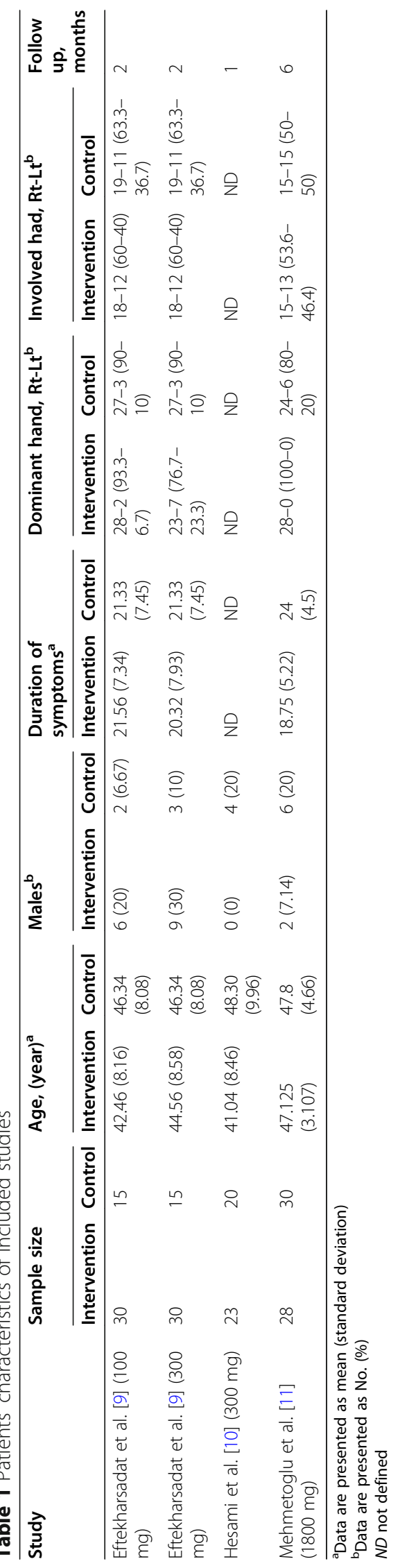




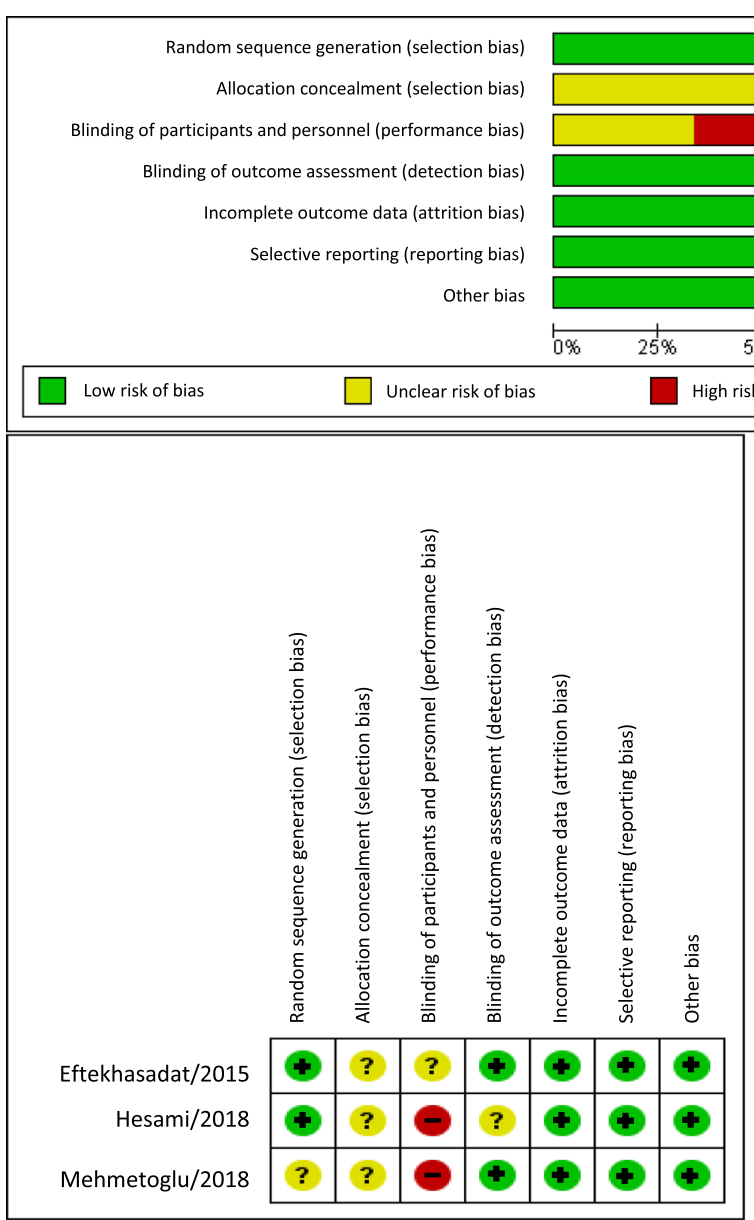

Fig. 2 Summary of quality assessment among included RCTs

groups before and after treatment could be detected [MD $(95 \%$ CI $)=-0.11(-0.70-0.48), p=0.718]$ (Fig. 3d) A significant heterogeneity was found between studies $\left[I^{2}=74.4 \%, p=0.009\right]$.

Pinch strength: monitoring effects of gabapentin using changes in pinch strength (pre- and post-treatment), there was no significant difference between intervention and control groups [MD $(95 \% \mathrm{CI})=0.72(-0.10-1.54)$, $p=0.083]$ (Fig. 3e) with evidence of heterogeneity $\left[I^{2}=\right.$ $79.4 \%, p=0.008]$.

Given the high level of heterogeneity in Mehmetoglu et al.'s [11] study in terms of a significant difference in the dose and the follow-up duration compared to the other two studies, a sub-analysis for the studies by Hesami et al. [10] and Eftekharsadat et al. [9] was carried out and the results are demonstrated in (Fig. 4).

\section{Discussion}

CTS is by far the most common entrapment neuropathy of the upper extremity [20]. While surgery is the treatment of choice in severe cases with evidence of severe nerve affection and cases refractory to conservative therapy [4], splinting with the addition of medications can provide some symptomatic relief in mild to moderate cases; however, controversy still exists regarding the use of Gabapentin as an adjuvant to splining.

In this systematic review and meta-analysis, we studied the benefit of adding Gabapentin to nocturnal splinting in the management of mild and moderate cases of CTS, and we found little evidence to support its effectiveness in improving the functional or electrophysiological outcomes.

Nocturnal splinting is a well-known conservative measure for symptomatic relief of CTS [21, 22]. Its effectiveness had been validated in previous studies [2325]. The rationale behind splinting is that it holds the wrist in the neutral position where the pressure on the median nerve is lowest, thus improving both clinical symptoms and electrophysiological studies $[26,27]$. It is an acceptable method for patients in the early phases of CTS, as it is simple, inexpensive, and it can be applied at home [28].

Previous studies have confirmed the effectiveness of gabapentin (1-[amino methyl]-cyclohexane acetic acid; Neurontin, Pfizer) in relieving neuropathic pain 
A

Study

TE seTE

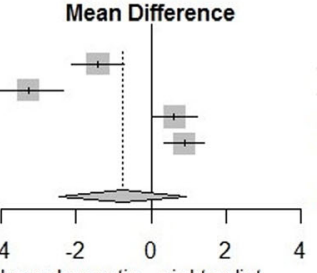

MD $\quad 95 \%-\mathrm{Cl}$ Weight

Eftekharsadat/2015/lran (100 mg gabapentin) -1.420 .3500$ Eftekharsadat/2015/ran (300 mg gabapentin) -3.260 .4672$

Hesami/2018/ran 0.620 .3131

Mehmetoglu/2018/Turkey

$\begin{array}{lll}0.89 & 0.2754\end{array}$

Random effects model

Heterogeneity: $\digamma^{2}=96 \%, \tau^{2}=2.8700, p<0.01$

$-1.42[-2.11 ;-0.74] \quad 25.0 \%$

$-3.26[-4.18 ;-2.35] \quad 24.3 \%$

$0.62[0.01 ; 1.24] \quad 25.2 \%$

0.89 [0.35; 1.43] $25.4 \%$

$-0.76[-2.46 ; 0.93] 100.0 \%$

splint plus gabapentin night splint

B

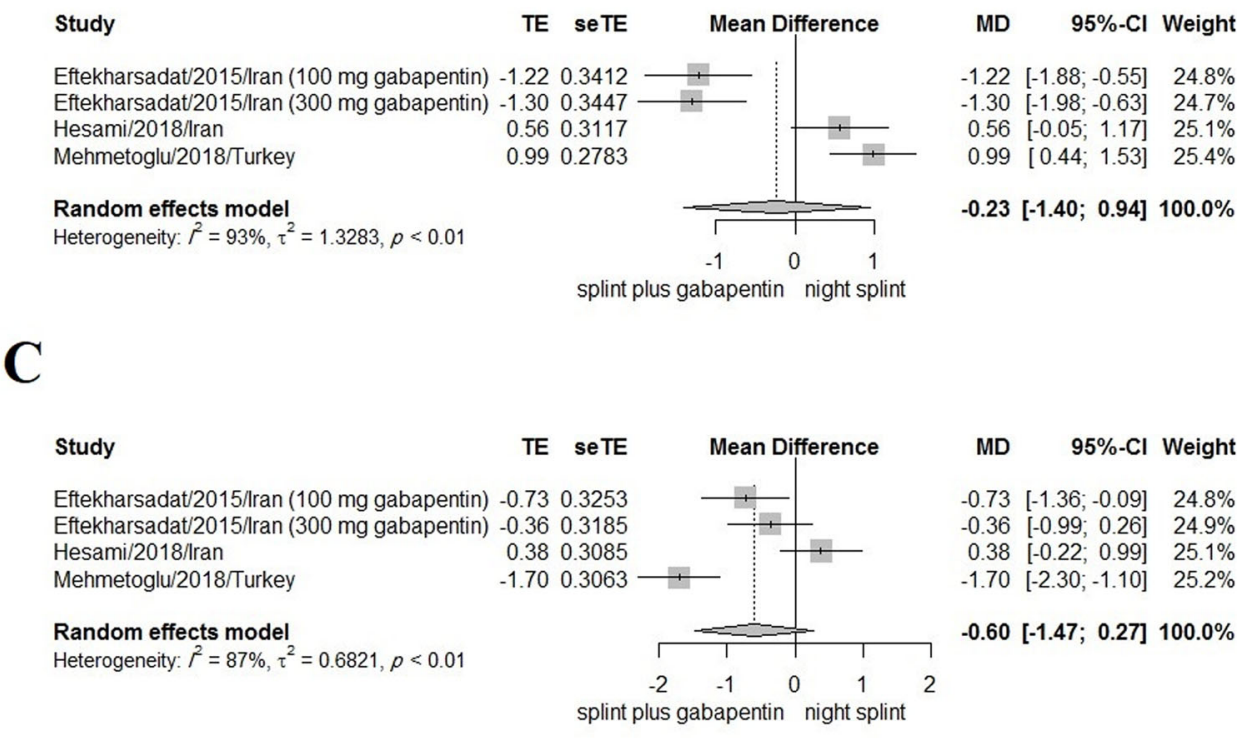

splint plus gabapentin night splint

$\mathbf{B}$

MD $95 \%-\mathrm{Cl}$ Weight

$-0.73[-1.36 ;-0.09] \quad 24.8 \%$

$-0.36[-0.99 ; 0.26] \quad 24.9 \%$

$0.38[-0.22 ; 0.99] \quad 25.1 \%$

$-1.70[-2.30 ;-1.10] \quad 25.2 \%$

$-0.60[-1.47 ; 0.27] 100.0 \%$

D
Study
TE seTE
Eftekharsadat/2015 (100 mg gabapentin) $0.30 \quad 0.3179$ Eftekharsadat/2015 (300 mg gabapentin) 0.390 .3188
Hesami/2018
$\begin{array}{rrr}-0.20 & 0.3065\end{array}$
Mehmetoglu/2018
$-0.870 .2748$
Random effects model
Heterogeneity: $\digamma^{2}=74 \%, \tau^{2}=0.2672, p<0.01$

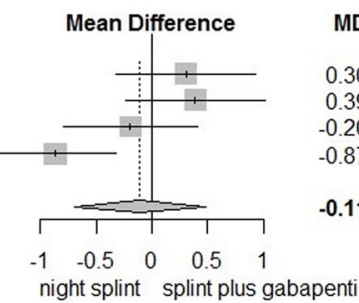
MD $\quad 95 \%-\mathrm{Cl}$ Weight
$0.30[-0.32 ; 0.93] \quad 24.4 \%$
$0.39[-0.24 ; 1.01] \quad 24.4 \%$
$-0.20[-0.80 ; 0.40] \quad 24.9 \%$
$0.87[-1.41 ;-0.33] \quad 26.3 \%$
$-0.11[-0.70 ; 0.48] 100.0 \%$

$\mathbf{E}$

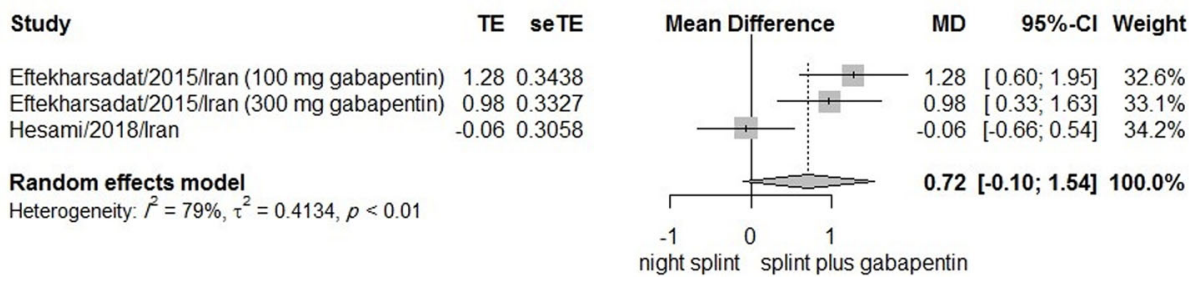

Fig. 3 Forest plot meta-analysis comparing changes in in the measured outcomes between gabapentin and control group; (TE = treatment effect, seTE = standard error of treatment effect): a Symptom Severity Scale (SSS), b Functional Severity Scale (FSS), c visual analogue score (VAS), d grip strength, and e pinch strength 
A

Study
TE se TE

B

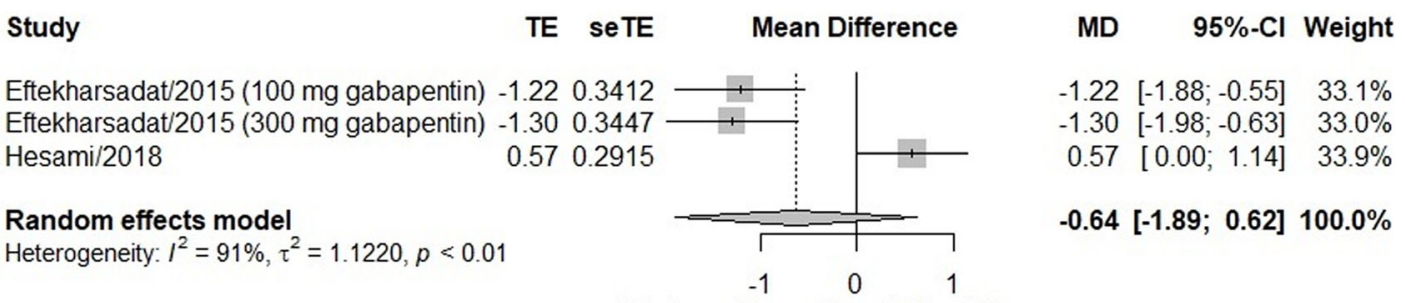

splint plus gabapentin night splint

C

Study

TE $\quad$ SeTE

Mean Difference

Eftekharsadat/2015 (100 mg gabapentin) -0.730 .3253$

Eftekharsadat/2015 (300 mg gabapentin) -0.360 .3185$

Hesami/2018

0.390 .2885

Random effects model

Heterogeneity: $I^{2}=72 \%, \tau^{2}=0.2451, p=0.03$

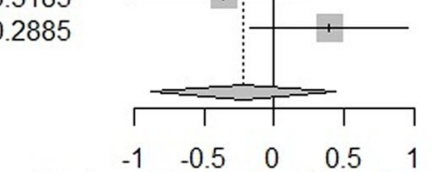

splint plus gabapentin night splint

\section{MD $\quad 95 \%-\mathrm{Cl}$ Weight}

$-0.73[-1.36 ;-0.09] \quad 32.5 \%$

$-0.36[-0.99 ; 0.26] \quad 32.9 \%$

$0.39[-0.17 ; 0.96] \quad 34.7 \%$

$-0.22[-0.88 ; 0.44] 100.0 \%$

D

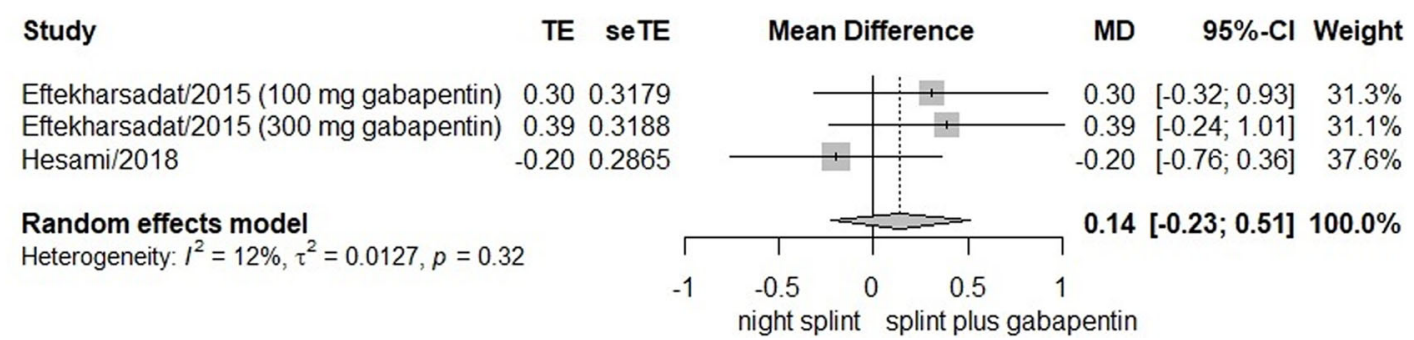

Fig. 4 Forest plot meta-analysis comparing changes between gabapentin and control group in the sub-group analysis; (TE = treatment effect, seTE = standard error of treatment effect): a Symptom Severity Scale (SSS), b Functional Severity Scale (FSS), c visual analogue score (VAS), and $\mathbf{d}$ grip strength 


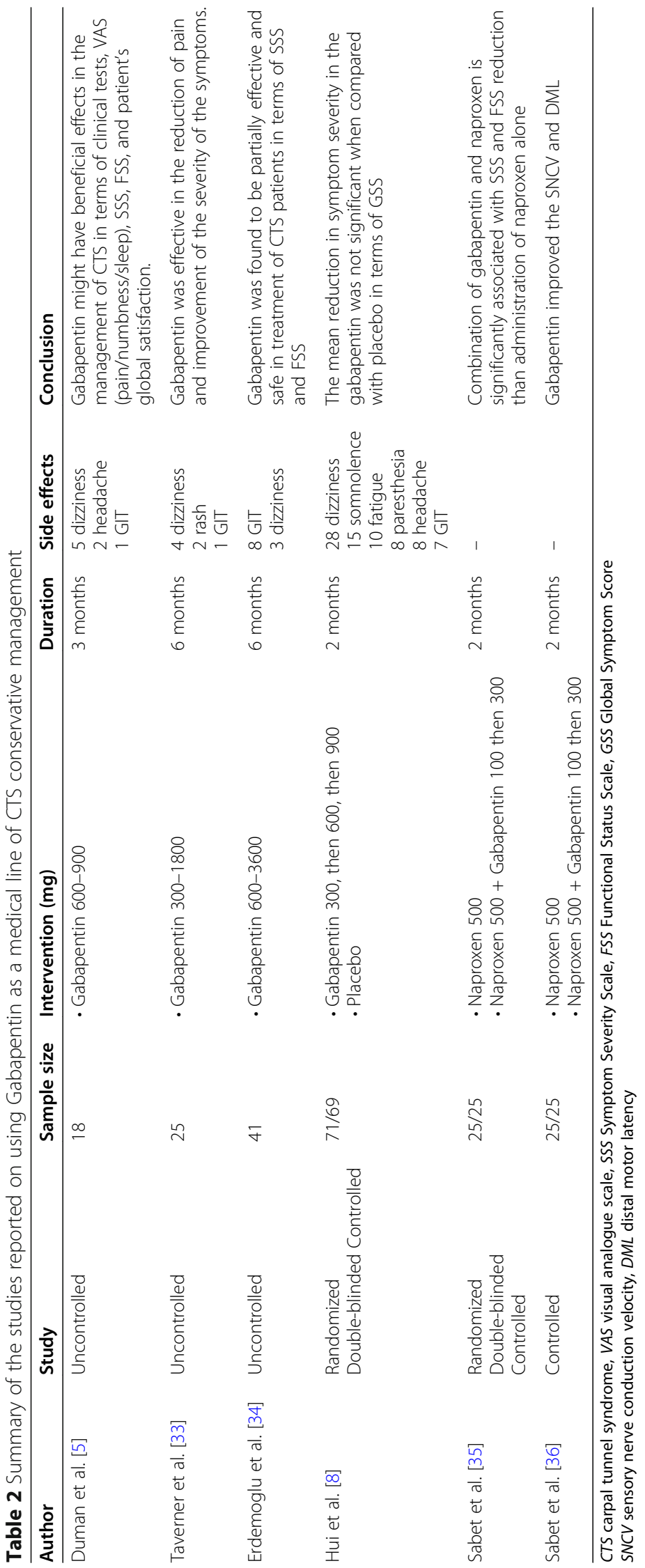


syndromes such as trigeminal neuralgia, diabetic neuropathy, reflex sympathetic dystrophy, multiple sclerosis, and post-herpetic neuralgia [29-32]. A randomized double-blinded placebo-controlled trail by Hui et al. concluded that its use alone in CTS is ineffective [8]. Reports on gabapentin role in CTS were summarized in Table $2[5,8,33-36]$. Since combined therapy is generally superior to monotherapy, other trails were performed to investigate the potential superiority of splinting combined with gabapentin over splinting alone. So, we included these trials in our analysis [9-11].

Eftekharsadat et al. [9] studied the effect of a low and high dose of gabapentin and compared their effects to a control group. At the same time, they found a significant improvement achieved by gabapentin regarding SSS, FSS, VAS, grip strength, and pinch strength; they concluded that as the dose of gabapentin increases, so does the effect.

The second study by Hesami et al. [10] showed that gabapentin has no statistically significant effect in mild cases, especially on grip strength but significantly improved the SSS, FSS, VAS, and grip strength in cases with moderate severity.

On the contrary, Mehmetoglu et al. [11] had some contradictory results; they found that the combination of splinting and gabapentin had no superior impact compared to splinting alone except when it comes to the median nerve sensory conduction velocity.

The heterogeneity of the conclusions in these studies can be attributed to the difference in their baseline criteria and the factors associated with the failure of conservative therapy in CTS. Predictors of failure of nonsurgical management in CTS include long duration of the symptoms, higher patients' age, and poor electrodiagnostic studies parameters such as prolonged motor and sensory latencies, and significant evidence of nerve injury.

This can partially explain why Mehmetoglu et al. [11] failed to prove the superiority of the combined treatment over splinting alone as in their study, the patients were older (median age was 47 and 49 years respectively) and the duration of the symptoms was longer (21 and 24 months respectively).

Hesami et al. [10], on the other hand, showed the superiority of the combined treatment in some parameters with a mean age in the gabapentin receiving group of 40 years and the duration of the sensory symptoms was at least 3 months.

Another important difference between these studies was the follow-up duration, while Mehmetoglu et al. [11] had 6 months follow up duration, the other two studies only followed the patients for 1 or 2 months; this may give the impression that gabapentin can improve the symptoms on the short but not on the long term.
The difference in doses was a critical factor as well. Mehmetoglu et al. [11] used $1800 \mathrm{mg}$, while the other two studies used 100 or $300 \mathrm{mg}$.

Some adverse effects of gabapentin have been reported in the literature including headache, dizziness, rash, and GIT symptoms causing some patients to abandon the trials $[5,8,11,34,37]$. On the other hand, Eftekharsadat et al. [9] used relatively lower doses of gabapentin (100 $\mathrm{mg}$ and $300 \mathrm{mg}$ ) and did not report any side effects.

\section{Limitations}

There are some limitations to our study. We had to include only three trials with a relatively small, overall and per study, sample size with high type 1 error in the study by Hesami et al. [10]. The studies used different doses of the drug which may have interfered with the effect in each study; the follow-up duration in some studies was not long enough to reflect the long-term effect of gabapentin and they were single-blinded. These drawbacks hindered an analysis with high power or a metaregression to tackle the clinical heterogeneity between the studies. Although our review is conclusive of the relevant literature, more powerful and well-designed studies are recommended to find evidence of higher quality.

\section{Conclusion}

This review suggests no benefit of gabapentin for symptomatic relief or improvement of grip or power strength in patients with mild to moderate CTS. Nevertheless, the low quality of evidence, small sample sizes, and heterogeneity of trial designs prohibit the establishment of a solid conclusion regarding the superiority of gabapentin plus splinting over splinting alone.

\section{Abbreviations \\ CTS: Carpal tunnel syndrome; RCTS: Randomized clinical trials; GABA: Gama- amino butyric acid; CENTRAL: Cochrane Central Register of Controlled Trials (CENTRAL); ISI: International Scientific Indexing; GHL: Global Health Library; VHL: Virtual Health Library; NYAM: New York Academy of Medicine; ICTRP: International Clinical Trials Registry Platform; SIGLE: System for Information on Grey Literature in Europe; MD: Mean difference; SMD: Standardized mean difference; Se: Standard errors; SD: Standard deviation; EMG: Electromyography; SSS: Symptom Severity Scale; FSS: Functional Severity Scale; VAS: Visual analogue score; Cl: Confidence interval; mg: Milligram}

\section{Authors' contributions}

AAK and AMA carried out the study conception and design. AMA and OGH carried out data acquisition. AMA, OGH, and AAK carried out analysis and interpretation of data, drafted the manuscript, and designed the figures. AAK did the critical revision. All authors discussed the results and commented on the manuscript. All authors read and approved the final manuscript.

\section{Funding}

This research did not receive any specific grant from funding agencies in the public, commercial, or not-for-profit sectors.

Availability of data and materials

The data supporting the results of this article are included within the article. 


\section{Ethics approval and consent to participate}

N/A

\section{Consent for publication}

N/A.

\section{Competing interests}

The authors declare that they have no conflict of interest.

\section{Author details}

'Orthopedic and Traumatolgy Department, Qena Faculty of Medicine and University Hospital, South Valley University, Qena, Egypt. ${ }^{2}$ General Surgery Department, Qena Faculty Of Medicine and University Hospital, South Valley University, Qena, Egypt.

Received: 10 July 2020 Accepted: 20 October 2020

Published online: 04 November 2020

\section{References}

1. Aroori S, Spence RA. Carpal tunnel syndrome. Ulster Med J. 2008;77(1):6-17.

2. Shiri R, Miranda H, Heliovaara M, Viikari-Juntura E. Physical work load factors and carpal tunnel syndrome: a population-based study. Occup Environ Med. 2009:66(6):368-73.

3. Dale AM, Harris-Adamson C, Rempel D, Gerr F, Hegmann K, Silverstein B, et al. Prevalence and incidence of carpal tunnel syndrome in US working populations: pooled analysis of six prospective studies. Scand J Work Environ Health. 2013;39(5):495-505.

4. Osterman AL, Whitman M, Porta LD. Nonoperative carpal tunnel syndrome treatment. Hand Clin. 2002;18(2):279-89.

5. Duman I, Aydemir K, Ozgul A, Kalyon TA. Assessment of the efficacy of gabapentin in carpal tunnel syndrome. J Clin Rheumatol. 2008;14(3):175-7.

6. Serpell MG. Neuropathic pain study g. Gabapentin in neuropathic pain syndromes: a randomised, double-blind, placebo-controlled trial. Pain. 2002; 99(3):557-66.

7. Taylor CP, Gee NS, Su TZ, Kocsis JD, Welty DF, Brown JP, et al. A summary of mechanistic hypotheses of gabapentin pharmacology. Epilepsy Res. 1998: 29(3):233-49.

8. Hui AC, Wong SM, Leung HW, Man BL, Yu E, Wong LK. Gabapentin for the treatment of carpal tunnel syndrome: a randomized controlled trial. Eur J Neurol. 2011;18(5):726-30.

9. Eftekharsadat B, Babaei-Ghazani A, Habibzadeh A. The efficacy of 100 and $300 \mathrm{mg}$ gabapentin in the treatment of carpal tunnel syndrome. Iran J Pharm Res. 2015;14(4):1275-80

10. Hesami O, Haghighatzadeh M, Lima BS, Emadi N, Salehi S. The effectiveness of gabapentin and exercises in the treatment of carpal tunnel syndrome: a randomized clinical trial. J Exerc Rehabil. 2018;14(6):1067-73.

11. Mehmetoglu O, Tascioglu F, Bakilan F, Armagan O. Efficacy of splint treatment or splint plus gabapentin treatment in idiopathic carpal tunnel syndrome. J Clin Anal Med. 2018:9(2):116-20.

12. Team RC. R: A language and environment for statistical computing. $R$ Foundation for Statistical Computing: Vienna, Austria; 2017.

13. Hedges LV, Pustejovsky JE, Shadish WR. A standardized mean difference effect size for multiple baseline designs across individuals. Res Synth Methods. 2013:4(4):324-41.

14. Schwarzer G. meta: An R package for meta-analysis. R news. 2007;7(3):40-5.

15. Mantel N, Haenszel W. Statistical aspects of the analysis of data from retrospective studies of disease. J Natl Cancer Inst. 1959;22(4):719-48.

16. DerSimonian R, Laird N. Meta-analysis in clinical trials. Control Clin Trials. 1986;7(3):177-88

17. Higgins JP, Thompson SG, Deeks JJ, Altman DG. Measuring inconsistency in meta-analyses. BMJ. 2003;327(7414):557-60.

18. Werner RA, Andary M. Electrodiagnostic evaluation of carpal tunnel syndrome. Muscle Nerve. 2011:44(4):597-607.

19. Higgins JP, Altman DG, Gotzsche PC, Juni P, Moher D, Oxman AD, et al. The Cochrane Collaboration's tool for assessing risk of bias in randomised trials. BMJ. 2011;343:d5928

20. Wipperman J, Goerl K. Carpal tunnel syndrome: diagnosis and management. Am Fam Physician. 2016;94(12):993-9.

21. Katz JN, Keller RB, Simmons BP, Rogers WD, Bessette L, Fossel AH, et al. Maine carpal tunnel study: outcomes of operative and nonoperative therapy for carpal tunnel syndrome in a community-based cohort. J Hand Surg Am. 1998:23(4):697-710

22. Scholten RJ, de Krom MC, Bertelsmann FW, Bouter LM. Variation in the treatment of carpal tunnel syndrome. Muscle Nerve. 1997;20(10):1334-5.

23. Piazzini DB, Aprile I, Ferrara PE, Bertolini C, Tonali P, Maggi L, et al. A systematic review of conservative treatment of carpal tunnel syndrome. Clin Rehabil. 2007;21(4):299-314.

24. Kuo MH, Leong CP, Cheng YF, Chang HW. Static wrist position associated with least median nerve compression: sonographic evaluation. Am J Phys Med Rehabil. 2001;80(4):256-60

25. Burke DT, Burke MM, Stewart GW, Cambre A. Splinting for carpal tunnel syndrome: in search of the optimal angle. Arch Phys Med Rehabil. 1994; 75(11):1241-4.

26. Page MJ, Massy-Westropp N, O'Connor D, Pitt V. Splinting for carpal tunnel syndrome. Cochrane Database Syst Rev. 2012;7:CD010003.

27. Kruger VL, Kraft GH, Deitz JC, Ameis A, Polissar L. Carpal tunnel syndrome: objective measures and splint use. Arch Phys Med Rehabil. 1991;72(7):517-20.

28. Halac G, Demir S, Yucel H, Niftaliyev E, Kocaman G, Duruyen H, et al. Splinting is effective for night-only symptomatic carpal tunnel syndrome patients. J Phys Ther Sci. 2015:27(4):993-6.

29. Mercadante S. Gabapentin in spinal cord injury pain. Pain Clinic. 1998;10(3): 203-6.

30. Backonja M, Beydoun A, Edwards KR, Schwartz SL, Fonseca V, Hes M, et al. Gabapentin for the symptomatic treatment of painful neuropathy in patients with diabetes mellitus: a randomized controlled trial. JAMA. 1998; 280(21):1831-6.

31. Rowbotham M, Harden N, Stacey B, Bernstein P, Magnus-Miller L. Gabapentin for the treatment of postherpetic neuralgia: a randomized controlled trial. JAMA. 1998;280(21):1837-42.

32. Nicholson B. Gabapentin use in neuropathic pain syndromes. Acta Neurol Scand. 2000:101(6):359-71.

33. Taverner D, Lisbona MP, Segales N, Docampo E, Calvet J, Castro S, et al. Efficacy of gabapentin in the treatment of carpal tunnel syndrome. Med Clin (Barc). 2008;130(10):371-3.

34. Erdemoglu AK. The efficacy and safety of gabapentin in carpal tunnel patients: open label trial. Neurol India. 2009;57(3):300-3.

35. Sabet R, Rahmanian K, Jahromi AS, Madani A. Analgesic effect of gabapentin in patients with carpal tunnel syndrome. J Appl Pharm Sci. 2017;7(06):079-82

36. Sabet R, Rahmanian K, Jahromi AS, Madani A. Effect of Gabapentin on nerve conduction studies in carpal tunnel syndrome. Biomed Res Ther. 2018:5(1): $1923-30$

37. Taverner D, Lisbona MP, Segales N, Docampo E, Calvet J, Castro S, et al. Efficacy of gabapentin in the treatment of carpal tunnel syndrome. [Spanish] Eficacia de la gabapentina en el tratamiento del sindrome del tunel carpiano. Med Clin. 2008:130(10):371-3.

\section{Publisher's Note}

Springer Nature remains neutral with regard to jurisdictional claims in published maps and institutional affiliations.

\section{Submit your manuscript to a SpringerOpen ${ }^{\circ}$ journal and benefit from:}

- Convenient online submission

- Rigorous peer review

- Open access: articles freely available online

- High visibility within the field

- Retaining the copyright to your article

Submit your next manuscript at $\boldsymbol{\nabla}$ springeropen.com 